\title{
Clinical complications during early treatment of anterior open bite
}

\section{Paulo Henrique ROSSATO(a) ID Letícia Batista BAYER ${ }^{(a)}$ \\ Renato Rodrigues de ALMEIDA(a) \\ Ana Cláudia de Castro Ferreira CONTI(a) ID \\ Thais Maria Freire FERNANDES(a) \\ Paula Vanessa Pedron \\ OLTRAMARI(a) iD}

(a) Universidade Norte do Paraná - Unopar, School of Dentistry, Department of Orthodontics, Londrina, PR, Brazil.

Declaration of Interests: The authors certify that they have no commercial or associative interest that represents a conflict of interest in connection with the manuscript.

Corresponding Author: Paula Vanessa Pedron Oltramari E-mail: pvoltramari@hotmail.com

ht1ps://doi.org/10.1590/1807-3107bor-2021.vol35.0081

Submitted: Juy 22, 2020

Accepted for publication: November 19, 2020

Last revision: December 17, 2020
Abstract: The object of this study was to compare the clinical complications of 4 different appliances used in the early treatment of anterior open bite (AOB), and to test the null hypothesis that there is no difference in the number of complications among the appliances. Records from 99 Class I malocclusion patients with AOB treated using bonded spurs, BS, $\mathrm{n}=25$; chin cup, $\mathrm{CC}, \mathrm{n}=25$; fixed palatal crib, FPC, $\mathrm{n}=25$; and removable palatal crib, $\mathrm{RPC}, \mathrm{n}=24$ ) were examined. The total number and frequency of clinical complications that occurred over 12 months were described and compared by using chi-square and Kruskal-Wallis tests (Dunn's post-test) ( $\alpha=5 \%, \mathrm{CI}=95 \%)$. The incidence of clinical complications was $66.7 \%$, comprising: breakage, bond failure, maladjustment, allergy, soft-tissue lesion, loss of removable appliance and abandonment. Eighteen patients gave up treatment; this occurred more frequently in the groups with removable appliances. Regarding the total number of complications per patient, Group BS exhibited a significantly higher number than the other groups ( $p<0.0001)$. A low frequency of complications (1 to 3) was found in the groups, except for Group BS, in which $8 \%$ of the patients presented moderate frequency (4 to 6 ). In terms of appliance types (fixed or removable), there was no difference in the incidence of complications ( $p>0.094$ ). The null hypothesis was rejected, since the BS group exhibited the highest total number and frequency of complications. There was no difference between fixed and removable appliances in terms of incidence of clinical complications, although more patients using removable appliances abandoned their treatment.

Keywords: Orthodontics; Open Bite; Orthodontics, Interceptive.

\section{Introduction}

The treatment of anterior open bite (AOB) is a challenge, ${ }^{1,2,3,4,5,6}$ because mechanical techniques must be combined with both personal motivation and abstinence from certain habits. Moreover, the cooperation of the patient and his/her parents plays an important role in the success of the treatment, regardless of whether the appliance is removable or fixed. Several studies $7,8,9,10,11,12,13,14,15,16,17,18,19,20$ have shown good results in correcting $\mathrm{AOB}$ in growing patients, and clinical success in the use of several fixed and removable devices, available in a variety of shapes and designs.

Although the dentoskeletal characteristics associated with AOB can lead to the selection of different protocols and appliances, the preference 
of the professional and the viability of the therapy should always be taken into consideration. Another important issue to bear in mind regards maintaining the integrity of the appliance. Clinical complications can prolong the treatment, and add to the cost and risks involved. ${ }^{19,21}$

Some clinical trials ${ }^{9,15,17,19}$ have reported complications of devices for AOB correction, such as occasional falling out and aspiration into the lungs, or accidental swallowing of the device, and irritation of the tip of the tongue, resulting in speech and chewing impairment. Such aspects could compromise the acceptance of appliances and toleration of patients during treatment, ultimately leading to rejection and abandonment of treatment.

Although some authors ${ }^{9,15,17,19}$ have reported problems with appliances in early $\mathrm{AOB}$ treatment, no studies have as yet evaluated these clinical complications objectively. Therefore, the aim of this study was to evaluate the number and frequency of clinical complications with four different appliances used in early AOB treatment: bonded spurs (BS), chin cup (CC), fixed palatal crib (FPC) and removable palatal crib (RPC), and to test the null hypothesis that there is no difference in the number of complications between the four types of appliances used to correct AOB.

\section{Methodology}

The University of North Parana Ethics Committee approved this retrospective study. The sample used in the study was obtained from an analysis of the orthodontic records of 99 patients who had a mean $\mathrm{AOB}$ of $3.7 \pm 1.77 \mathrm{~mm}$; $\min -1.0 \mathrm{~mm}$; $\max -8.5 \mathrm{~mm}$, Angle Class I malocclusion, and mean age of 8.4 years \pm 0.8 . They were randomly allocated to 4 treatment groups: bonded spurs on the palatal and lingual surfaces of the maxillary and mandibular central incisors (BS, $n=25)$; individualized chin cup adapted to each patient, so that the resulting force vector passed $45^{\circ}$ above the occlusal plane (CC, $\left.n=25\right)$; fixed palatal crib with palatal bars constructed with a 0.7-mm stainless steel wire welded to a palatal 0.9mm stainless steel arch (FPC, $\mathrm{n}=25)$ and removable palatal crib composed of a palatal bar, Adams' clasps on the maxillary permanent first molars, a labial archwire and acrylic coverage $(\mathrm{RPC}, \mathrm{n}=24)$ (Figure 1). The patients were monitored for a period of 12 months, as described in a previous study by Rossato et al. ${ }^{19}$

The patients received instructions on the use and care of the appliances during treatment. The treatment consisted of monthly appointments scheduled throughout the study evaluation period, in addition to emergency appointments, in satisfaction of the instructions given to patients and their guardians to advise the evaluators immediately should any complications arise. All procedures were detailed on individual clinical records.

For the purpose of this study, information applicable to the total number and frequency of clinical complications, such as bond failure, breakage of
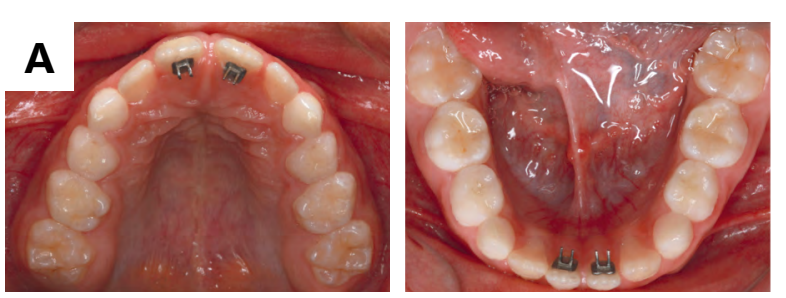

B

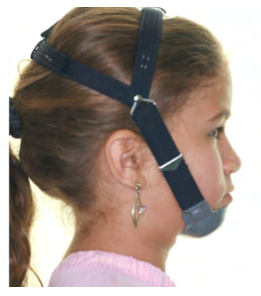

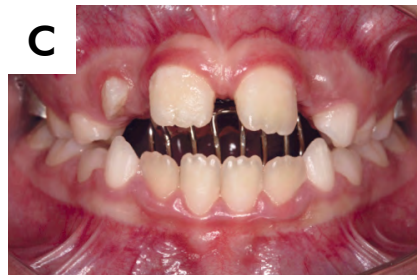
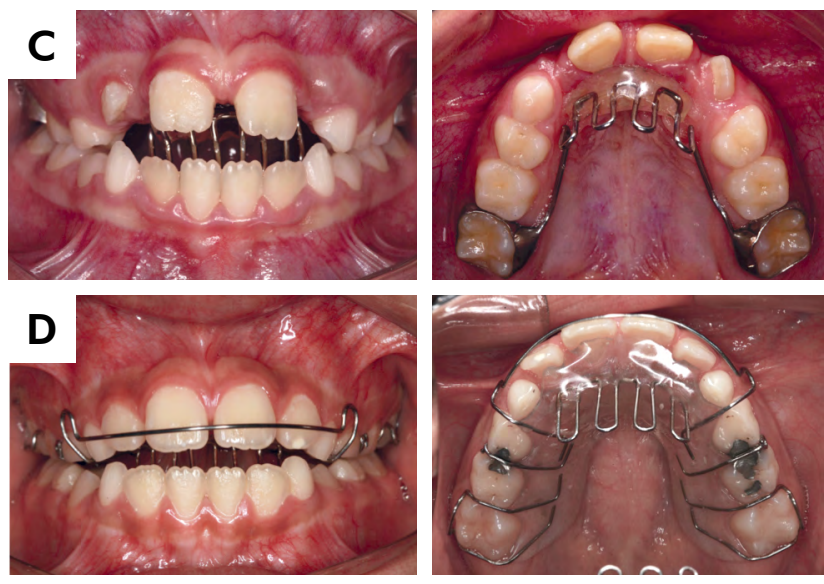

Figure 1. Appliances used: (A) bonded spurs (BS), (B) chin cup (CC), (C) fixed palatal crib (FPC), (D) removable palatal crib (RPC). 
appliance, maladjustment, allergy, soft-tissue lesions, loss of removable appliance and abandonment were assessed. Analysis of the frequency of complications consisted of performing a qualitative differentiation in four categories, in line with the proposal by Schiöth et al.:22 low frequency (1-3 complications), moderate frequency (4-6 complications), high frequency (7-10 complications), and very high frequency (more than 10 complications). The total number of complications during treatment, considering the appliance type (fixed or removable), was compared by dividing the data into: "absence of complications" and "at least one complication," in accordance with the study by Silva et al. ${ }^{23}$

\section{Statistical analysis}

The occurrence of complications among the groups was compared using the chi-squared test. The number of complications per patient in each group was evaluated by the Kruskal-Wallis test, followed by Dunn's post-hoc test. All tests were carried out using the IBM SPSS statistics 18.0 software program for Windows (New York, USA) $(\alpha=5 \%, C I=95 \%)$.

\section{Results}

After a period of 12 months, as previously described, ${ }^{19}$ there were no statistically significant intergroup differences for overbite correction. All of the tested treatment protocols (BS, CC, FPC, and RPC) were effective in reducing $A O B$ in $97.5 \%$ of the Class I children with a mean $\mathrm{AOB}$ reduction of $3.1 \mathrm{~mm}$.

During the period of evaluation, 33 patients $(33.3 \%)$ presented no complications. A total of 109 clinical complications were found in the records of 66 patients (66.7\%), most of which occurred in Group BS (23 patients), followed by Group CC (18 patients), Group RPC (14 patients) and Group FPC (11 patients). Just 2 patients (8\%), in Group BS, did not experience any clinical complications (Figure 2).

The clinical complications observed during the 12-month period are presented in Table 1. Eight types of clinical complications were reported, as follows: bond failure of the spur, breakage of the appliance, maladjustment, allergy, soft-tissue lesions, loss of removable appliance and abandonment. There was no record of any complications that would preclude continuation of the treatment or put the patients at risk.

Breakages, bond failure and maladjustment of appliances that required immediate repair to continue the treatment all occurred only once in all the groups except for the BS Group. In this group, bond failure occurred once in $36 \%$ of the patients, but higher rates of recurrence were also found ( 2 complications: $20 \%$, 3 complications: $28 \%$; 5 complications: $8 \%$ ) (Table 1).

Groups BS and RPC presented no complications related to allergy or soft-tissue lesions. However, $8 \%$ of the patients using the chin cup exhibited a skin allergy when using the device, and $12 \%$ of the patients using the fixed palatal crib presented some form of soft-tissue lesion (gums, mucosa or tongue) (Table 1).

Abandonment of treatment was also considered a clinical complication. In all, there were 18 such cases, which occurred more frequently in the groups with removable appliances $(C C=8$ patients and $\mathrm{RPC}=6$ patients) than in those with fixed appliances (BS $=3$ patients and FPC $=1$ ). The results for "loss" and "irregular use" complications - only possible with the removable appliances - occurred most frequently in Group CC (Table 1).

There was a significant difference among the groups with regard to the presence/absence of complications $(p=0.0028)$. Moreover, a higher percentage of low frequency of complications (1 to 3) was found in all the groups $(\mathrm{BS}=84 \%, \mathrm{CC}=72 \%, \mathrm{FPC}=44 \%$ and RPC 58.4\%), with the exception of group BS, where

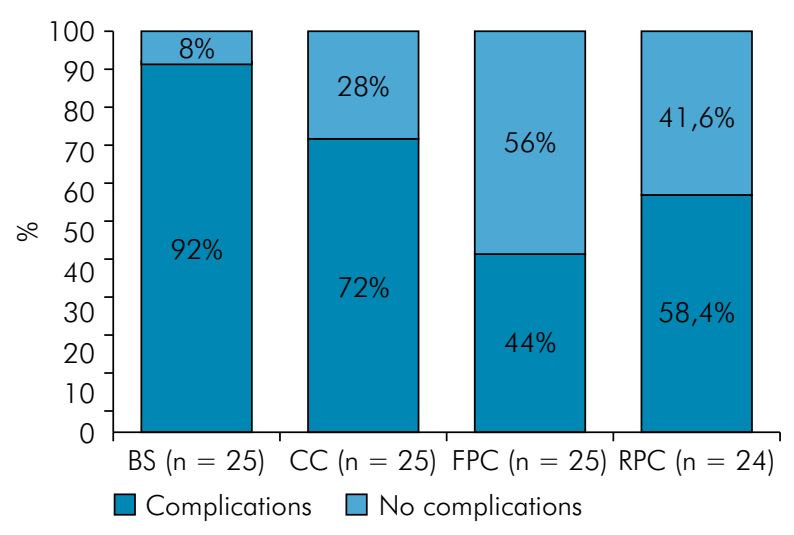

Figure 2. Incidence of complications in the following groups: bonded spurs (BS), chin cup (CC), fixed palatal crib (FPC) and removable palatal crib (RPC). 
Table 1. Type and number of complications for groups bonded spurs (BS), chin cup (CC), fixed palatal crib (FPC) and removable palatal crib (RPC).

\begin{tabular}{|c|c|c|c|c|c|c|c|c|c|}
\hline \multirow{3}{*}{ Type of complications } & \multirow{3}{*}{ Number of complications } & \multirow{2}{*}{\multicolumn{2}{|c|}{$\begin{array}{c}\text { BS Group } \\
n=25\end{array}$}} & \multirow{2}{*}{\multicolumn{2}{|c|}{$\begin{array}{c}\text { CC Group } \\
n=25\end{array}$}} & \multirow{2}{*}{\multicolumn{2}{|c|}{$\begin{array}{c}\text { FPC Group } \\
n=25\end{array}$}} & \multirow{2}{*}{\multicolumn{2}{|c|}{$\begin{array}{c}\text { RPC Group } \\
n=24\end{array}$}} \\
\hline & & & & & & & & & \\
\hline & & $\mathrm{n}$ & $\%$ & $\mathrm{n}$ & $\%$ & $\mathrm{n}$ & $\%$ & $\mathrm{n}$ & $\%$ \\
\hline \multirow{7}{*}{ Breakage, bond failure, maladjustment } & 0 & 2 & 8 & 22 & 88 & 18 & 72 & 19 & 81.2 \\
\hline & 1 & 9 & 36 & 3 & 12 & 7 & 28 & 5 & 20.8 \\
\hline & 2 & 5 & 20 & 0 & 0 & 3 & 12 & 0 & 0 \\
\hline & 3 & 7 & 28 & 0 & 0 & 0 & 0 & 0 & 0 \\
\hline & 4 & 0 & 0 & 0 & 0 & 0 & 0 & 0 & 0 \\
\hline & 5 & 2 & 8 & 0 & 0 & 0 & 0 & 0 & 0 \\
\hline & Total & 25 & 100 & 25 & 100 & 25 & 100 & 24 & 100 \\
\hline \multirow{3}{*}{ Allergy, mucosal injury } & 0 & 25 & 100 & 23 & 92 & 22 & 88 & 24 & 100 \\
\hline & 1 & 0 & 0 & 2 & 8 & 3 & 12 & 0 & 0 \\
\hline & Total & 25 & 100 & 25 & 100 & 25 & 100 & 24 & 100 \\
\hline \multirow{3}{*}{ Loss } & 0 & 25 & 100 & 23 & 92 & 25 & 100 & 23 & 96 \\
\hline & 1 & 0 & 0 & 2 & 8 & 0 & 0 & 1 & 4 \\
\hline & Total & 25 & 100 & 25 & 100 & 25 & 100 & 24 & 100 \\
\hline \multirow{4}{*}{ Irregular use } & 0 & 25 & 100 & 19 & 76 & 25 & 100 & 20 & 83 \\
\hline & 1 & 0 & 0 & 6 & 24 & 0 & 0 & 3 & 13 \\
\hline & 2 & 0 & 0 & 0 & 0 & 0 & 0 & 1 & 4 \\
\hline & Total & 25 & 100 & 25 & 100 & 25 & 100 & 24 & 100 \\
\hline \multirow{3}{*}{ Abandonment } & 0 & 22 & 88 & 17 & 68 & 24 & 96 & 18 & 75 \\
\hline & 1 & 3 & 12 & 8 & 32 & 1 & 4 & 6 & 25 \\
\hline & Total & 25 & 100 & 25 & 100 & 25 & 100 & 24 & 100 \\
\hline
\end{tabular}

Table 2. Frequency of clinical complications during treatment of $A O B$ in the tested groups.

\begin{tabular}{|c|c|c|c|c|c|c|c|c|c|}
\hline \multirow{2}{*}{ Frequency of complications } & \multicolumn{2}{|c|}{$B S(n=25)$} & \multicolumn{2}{|c|}{$C C(n=25)$} & \multicolumn{2}{|c|}{$\mathrm{FPC}(\mathrm{n}=25)$} & \multicolumn{2}{|c|}{$\operatorname{RPC}(n=24)$} & \multirow{2}{*}{ p-value* } \\
\hline & $\mathrm{n}$ & $\%$ & $\mathrm{n}$ & $\%$ & $\mathrm{n}$ & $\%$ & $\mathrm{n}$ & $\%$ & \\
\hline Absence of complication & 2 & 8.0 & 7 & 28.0 & 14 & 56.0 & 10 & 41.6 & \multirow{7}{*}{$0.0028^{* *}$} \\
\hline \multicolumn{9}{|l|}{ Presence of complication } & \\
\hline Low frequency (1-3 complications) & 21 & 84.0 & 18 & 72.0 & 11 & 44.0 & 14 & 58.4 & \\
\hline Moderate frequency (4-6 complications) & 2 & 8.0 & 0 & 0.0 & 0 & 0.0 & 0 & 0 & \\
\hline High frequency (7-10 complications) & 0 & 0.0 & 0 & 0.0 & 0 & 0.0 & 0 & 0 & \\
\hline Very high frequency (> 10 complications) & 0 & 0.0 & 0 & 0.0 & 0 & 0.0 & 0 & 0 & \\
\hline Total & 23 & 92.0 & 18 & 72.0 & 11 & 44.0 & 14 & 58.4 & \\
\hline $\begin{array}{l}\text { Complications per patient } \\
\text { Median (1Q/3Q) }\end{array}$ & \multicolumn{2}{|c|}{$2(2 / 1)^{a}$} & \multicolumn{2}{|c|}{$1(0 / 1)^{b}$} & \multicolumn{2}{|c|}{$0(0 / 1)^{b}$} & \multicolumn{2}{|c|}{$1(0 / 1)^{b}$} & $<0.0001^{* * *}$ \\
\hline
\end{tabular}

*Statistically significant; ${ }^{* *}$ Chi-square test; ${ }^{* * *}$ Kruskal-Wallis test (Dunn post-hoc). Different letters mean statistically significant different.

$8 \%$ of the patients presented moderate frequency (4 to 6). None of the groups monitored presented a high or very high frequency of complications. In addition, Group BS had a significantly higher number of complications per patient than the other groups evaluated $(p<0.0001)$ (Table 2).
Considering the types of appliance (fixed or removable), there was no difference in terms of the incidence of complications ( $p=0.94)$; that is to say, at least 1 complication occurred in $64 \%$ and $65 \%$ of the patients with fixed and removable appliances (Table 3), respectively. 
Table 3. Incidence of complications according to the type of device (fixed or removable).

\begin{tabular}{|c|c|c|c|c|c|}
\hline \multirow{3}{*}{ Complications } & \multicolumn{4}{|c|}{ Type of device } & \multirow{3}{*}{$\mathrm{p}$-value } \\
\hline & \multicolumn{2}{|c|}{ Fixed } & \multicolumn{2}{|c|}{ Removable } & \\
\hline & $\mathrm{n}$ & $\%$ & $\mathrm{n}$ & $\%$ & \\
\hline None & 16 & $32 \%$ & 17 & $35 \%$ & \multirow{2}{*}{0.94} \\
\hline At least one & 34 & $64 \%$ & 32 & $65 \%$ & \\
\hline
\end{tabular}

\section{Discussion}

Early treatment of anterior open bite $(\mathrm{AOB})$ consists of several possible therapies..$^{18}$ Although the effects of the treatment on the correction and stability of the results are regarded as the primary outcome, the variable nature of the devices gives rise to factors related to clinical indication. To this end, the choice of an appliance that gives good results must be coupled with its acceptance by both the professional and the patient. One of the most important considerations when selecting an appliance is the frequency of clinical complications and the financial implications..$^{23}$ Additionally, it is important to underscore that each patient must be treated individually in order to achieve the best results. Therefore, the etiology of AOB based on the type of oral habits and dentoskeletal/soft tissue factors can lead clinicians to choose different protocols and appliances.

Despite the various studies regarding early treatment of $\mathrm{AOB}, 9,10,11,12,13,14,15,16,17,18,19$ there are no comparisons of clinical complications to help the professional choose the most indicated appliance. Several authors ${ }^{9,17,19}$ have stressed their concern regarding the bond failure of spurs, in spite of their effectiveness in treating $\mathrm{AOB}$, a factor that should be considered when choosing the appliance. Therefore, to the best of our knowledge, this is the first study investigating the clinical complication of devices used in early treatment of AOB.

One of the professionals' major concerns when selecting an appliance is the patients' tissue lesions. ${ }^{17}$ Soft-tissue injuries were observed in $12 \%$ of the patients in the FPC group, but were not seen in the RPC or BS groups. Additionally, two patients from the CC group reported skin allergy in the region of the chin in contact with the device. As for the RPC group, since the chin cup is a removable appliance, it was possible to remove the appliance during meals, thus minimizing the chance of lesions during treatment. The absence of soft-tissue lesions may be explained by the greater acceptance of the use of particular devices, as evaluated by Canuto et al., ${ }^{17}$ who found that $92.5 \%$ of the patients became accustomed to the bonded spurs after a week. These results were related to the natural adaptations made the patients during the chewing and swallowing functions.

Despite the constant instructions and guidance given to patients and their guardians in regard to using and caring for their appliance, ${ }^{19}$ there were several reported losses and irregular uses of the removable devices in the present study. Given the limitations of these removable devices, their use has diminished over the years, even though they continue to be recommended more specifically during the period of the mixed dentition. ${ }^{24} \mathrm{~A}$ further concern of the professional is the tendency to abandon treatment, possibly because the patient does not accept the proposed therapy. ${ }^{25}$ The present study found a higher frequency of patients abandoning treatment in Group CC, followed by Group RPC (32\% and 25\%, respectively). This may be attributed to a number of reasons regarding the devices, mostly that they are removable and thus require patient cooperation, and that they may cause discomfort and be regarded as antiesthetic. It is noteworthy to mention that the study data were obtained from a randomized clinical study, ${ }^{19}$ in which the patients were randomly assigned to treatment groups.

Although the complications observed in the current study were rated as having high occurrence, they were mostly classified as "low frequency", i.e., they occurred 1 to 3 times during the period of observation. ${ }^{22}$ Only Group BS presented moderate frequency (4 to 6 complications) in $8 \%$ of the patients. The results of the present study differed from those observed in the studies of treatment for Class II malocclusion with functional appliances, ${ }^{22,23,26}$ in which a high and very high frequency of complications were found. These results are probably attributed to needing frequent reactivations, which could ultimately weaken the system.

The group treated with the bonded spurs had a significantly higher number of complications per 
patient than the other groups, resulting from the bond failure of the devices, which occurred at least once in $92 \%$ of the BS group, and leading to a greater number of clinical interventions.

When comparing fixed and removable appliances, the present study also found that there was no difference in terms of the incidence of clinical complications. Despite the similar results in the correction of $\mathrm{AOB}$ found in the literature using various types of appliances, ${ }^{9,10,11,17,19,27}$ about $65 \%$ of the patients presented at least one clinical complication during treatment. Moreover, the type of clinical complication may induce the choice of appliance, as was the case of the present study, in which the fixed appliances presented a higher frequency of complications that required repair or a new device to be fabricated. Comparatively, the removable appliances presented complications inherent to the patients' cooperation in using the appliance. Esthetics and discomfort were not evaluated in the present study, but may nevertheless have an influence on the level of cooperation..$^{17,21}$

A limitation of this study was not to have considered patient cooperation during treatment, or assessed the patients' perceived satisfaction. This could have been evaluated through a questionnaire evaluating use of the appliances or quality of life. Different designs of appliances were evaluated; therefore, the questionnaire could have had suggested which one represented better acceptance of the treatment.

Despite the clinical complications of bond failure found in this study, bonded spurs ${ }^{9,15,17,19}$ have the advantage of simplicity of installation and low cost, as corroborated by previous studies. ${ }^{15}$ Comparatively, fixed and removable cribs still require a laboratory phase, which represents a disadvantage when compared with the bonded spur. A future study could consider the economic results weighed together with the financial implications of treatment, using costbenefit analyses. ${ }^{21}$ These could provide information on what devises are the most cost-efficient.

\section{Conclusion}

The null hypothesis was rejected, since the BS group showed the highest total number and frequency of complications. There was no difference between fixed and removable appliances in terms of incidence of clinical complications, although more patients using removable appliances abandoned their treatment.

\section{Acknowledgment}

This study was supported by Fundação Nacional de Desenvolvimento do Ensino Superior Particular (FUNADESP).

\section{References}

1. Atkinson SR. "Open-bite" malocclusion. Am J Orthod. 1966 Dec;52(12):877-86. https://doi.org/10.1016/0002-9416(66)90191-6

2. Gershater MM. The proper perspective of open bite. Angle Orthod. 1972 Jul;42(3):263-72. https://doi.org/10.1043/0003-3219(1972)042<0263:TPPOOB>2.0.CO;2

3. Kim YH. Overbite depth indicator with particular reference to anterior open-bite. Am J Orthod. 1974 Jun;65(6):586-611. https://doi.org/10.1016/0002-9416(74)90255-3

4. Nahoum HI. Anterior open-bite: a cephalometric analysis and suggested treatment procedures. Am J Orthod. 1975 May;67(5):523-21. https://doi.org/10.1016/0002-9416(75)90297-3

5. Subtelny JD, Sakuda M. Open-bite: diagnosis and treatment. Am J Orthod. 1964;50(5):337-58. https://doi.org/10.1016/0002-9416(64)90175-7

6. Huang GJ, Justus R, Kennedy DB, Kokich VG. Stability of anterior openbite treated with crib therapy. Angle Orthod. 1990;60(1):17-24. https://doi.org/10.1043/0003-3219(1990)060<0017:SOAOTW>2.0.CO;2

7. Pithon MM, Magno MB, Coqueiro RS, Paiva SM, Marques LS, Paranhus LR, et al. Oral health-related quality of life of children before, during, and after anterior open bite correction: a single-blinded randomized controlled trial. Am J Orthod Dentofacial Orthop. 2019 Sep;156(3):303-11. https://doi.org/10.1016/j.ajodo.2019.04.022

8. Dias FA, Assis Urnau FD, Pedron Oltramari PV, Lupion Poleti M, Almeida MR, Freire Fernandes TM. Stability of early treatment of anterior open bite: clinical performance of bonded lingual spurs. J Orthod. 2019 Mar;46(1):68-73. https://doi.org/10.1177/1465312519827601 
9. Cassis MA, Almeida RR, Janson G, Almeida-Pedrin RR, Almeida MR. Treatment effects of bonded spurs associated with high-pull chincup therapy in the treatment of patients with anterior open bite. Am J Orthod Dentofacial Orthop. 2012 Oct;142(4):487-93. https://doi.org/10.1016/i.ajodo.2012.04.022

10. Torres F, Almeida RR, Almeida MR, Almeida-Pedrin RR, Pedrin F, Henriques JF. Anterior open bite treated with a palatal crib and high-pull chin cup therapy. A prospective randomized study. Eur J Orthod. 2006 Dec;28(6):610-7. https://doi.org/10.1093/ejo/cil053

11. Pedrin F, Almeida MR, Almeida RR, Almeida-Pedrin RR, Torres F. A prospective study of the treatment effects of a removable appliance with palatal crib combined with high-pull chincup therapy in anterior open-bite patients. Am J Orthod Dentofacial Orthop. 2006 Mar;129(3):418-23. https://doi.org/10.1016/j.ajodo.2005.04.035

12. Cozza P, Baccetti T, Franchi L, McNamara JA Jr. Treatment effects of a modified quad-helix in patients with dentoskeletal open bites. Am J Orthod Dentofacial Orthop. 2006 Jun;129(6):734-9. https://doi.org/10.1016/j.ajodo.2006.02.004

13. Erbay E, Uğur T, Ulgen M. The effects of Frankel's function regulator (FR-4) therapy on the treatment of Angle Class I skeletal anterior open bite malocclusion. Am J Orthod Dentofacial Orthop. 1995 Jul;108(1):9-21. https://doi.org/10.1016/S0889-5406(95)70061-7

14. Insabralde NM, Almeida RR, Henriques JF, Fernandes TM, Flores-Mir C, Almeida MR. Dentoskeletal effects produced by removable palatal crib, bonded spurs, and chincup therapy in growing children with anterior open bite. Angle Orthod. 2016 Nov;86(6):969-75. https://doi.org/10.2319/011916-49.1

15. Leite JS, Matiussi LB, Salem AC, Provenzano MG, Ramos AL. Effects of palatal crib and bonded spurs in early treatment of anterior open bite: a prospective randomized clinical study. Angle Orthod. 2016 Sep;86(5):734-9. https://doi.org/10.2319/031815-170.1

16. Mucedero M, Vitale M, Franchi L, Cozza P, Perillo L. Comparisons of two protocols for early treatment of anterior open bite. Eur J Orthod. 2017 Jun;39(3):270-6.

17. Canuto LF, Janson G, Lima NS, Almeida RR, Cançado RH. Anterior open-bite treatment with bonded vs conventional lingual spurs: A comparative study. Am J Orthod Dentofacial Orthop. 2016 Jun;149(6):847-55. https://doi.org/10.1016/i.ajodo.2015.11.026

18. Feres MF, Abreu LG, Insabralde NM, Almeida MR, Flores-Mir C. Effectiveness of open bite correction when managing deleterious oral habits in growing children and adolescents: a systematic review and meta-analysis. Eur J Orthod. 2017 Feb;39(1):31-42. https://doi.org/10.1093/ejo/cjw005

19. Rossato PH, Fernandes TM, Urnau FD, Castro AC, Conti F, Almeida RR, et al. Dentoalveolar effects produced by different appliances on early treatment of anterior open bite: a randomized clinical trial. Angle Orthod. 2018 Nov;88(6):684-91. https://doi.org/10.2319/101317-691.1

20. Slaviero T, Fernandes TM, Oltramari-Navarro PV, Castro AC, Conti F, Poleti ML, et al. Dimensional changes of dental arches produced by fixed and removable palatal cribs: A prospective, randomized, controlled study. Angle Orthod. 2017 Mar;87(2):215-22. https://doi.org/10.2319/060116-438.1

21. Wiedel AP, Norlund A, Petrén S, Bondemark L. A cost minimization analysis of early correction of anterior crossbite-a randomized controlled trial. Eur J Orthod. 2016 Apr;38(2):140-5. https://doi.org/10.1093/ejo/cjv026

22. Schiöth T, Bremen J, Pancherz H, Ruf S. Complications during Herbst appliance treatment with reduced mandibular cast splints: a prospective, clinical multicenter study. J Orofac Orthop. 2007 Jul;68(4):321-7. https://doi.org/10.1007/s00056-007-0703-4

23. Silva JF, Gerszewski C, Moresca RC, Correr GM, Flores-Mir C, Moro A. Retrospective study of clinical complications during orthodontic treatment with either a removable mandibular acrylic splint Herbst or with a cantilever Herbst. Angle Orthod. 2015 Jan;85(1):64-71. https://doi.org/10.2319/122113-936.1

24. Littlewood SJ, Tait AG, Mandall NA, Lewis DH. The role of removable appliances in contemporary orthodontics. Br Dent. 2001 Sep 22;191(6):304-6, 9-10. https://doi.org/10.1038/sj.bdj.4801170

25. Bell ML, Kenward MG, Fairclough DL, Horton NJ. Differential dropout and bias in randomised controlled trials: when it matters and when it may not. BMJ. 2013 Jan;346 jan21 1:e8668. https://doi.org/10.1136/bmi.e8668

26. Wiechmann D, Vu J, Schwestka-Polly R, Helms HJ, Knösel M. Clinical complications during treatment with a modified Herbst appliance in combination with a lingual appliance. Head Face Med. 2015 Sep;11(1):31. https://doi.org/10.1186/s13005-015-0088-3

27. Torres FC, Almeida RR, Almeida-Pedrin RR, Pedrin F, Paranhos LR. Dentoalveolar comparative study between removable and fixed cribs, associated to chincup, in anterior open bite treatment. J Appl Oral Sci. 2012 Sep-Oct;20(5):531-7.

https://doi.org/10.1590/S1678-77572012000500007 